\title{
The efficacy of the self-adjusting file and ProTaper for removal of calcium hydroxide from root canals
}

\author{
Gisele FARIA ${ }^{1}$, Milton Carlos KUGA 1 , Alessandra Camila RUY², Arturo Javier ARANDA-GARCIA ${ }^{3}$, Idomeo BONETTI- \\ FILHO $^{4}$, Juliane Maria GUERREIRO-TANOMARU1', Renato Toledo LEONARDO ${ }^{4}$ \\ 1- DDS, MSc, PhD, Assistant Professor, Department of Restorative Dentistry, Araraquara Dental School, UNESP - Univ. Estadual Paulista, Araraquara, SP, Brazil. \\ 2- DDS, Araraquara Dental School, UNESP - Univ. Estadual Paulista, Araraquara, SP, Brazil. \\ 3- DDS, MSc, PhD, Member of Mexican Navy. \\ 4- DDS, MSc, PhD, Associate Professor, Department of Restorative Dentistry, Araraquara Dental School, UNESP - Univ. Estadual Paulista, Araraquara, SP, Brazil.
}

Corresponding address: Gisele Faria - Faculdade de Odontologia de Araraquara - UNESP - Departamento de Odontologia Restauradora - Rua Humaitá, 1680 - 14801-903 - Araraquara - SP - Brasil - Phone: +55-16-3301-6398 - Fax: +55-16-3301-6392 - e-mail: giselefaria@foar.unesp.br

Submitted: January 8, 2013 - Modification: April 12, 2013 - Accepted: June 20, 2013

\section{ABSTRACT}

\begin{abstract}
$\mathrm{O}$ bjective: The goal of this study was to evaluate the efficacy of the Self-Adjusting File (SAF) and ProTaper for removing calcium hydroxide $\left[\mathrm{Ca}(\mathrm{OH})_{2}\right]$ from root canals. Material and Methods: Thirty-six human mandibular incisors were instrumented with the ProTaper system up to instrument F2 and filled with a $\mathrm{Ca}(\mathrm{OH})_{2}$-based dressing. After 7 days, specimens were distributed in two groups $(n=15)$ according to the method of $\mathrm{Ca}(\mathrm{OH})_{2}$ removal. Group I (SAF) was irrigated with $5 \mathrm{~mL}$ of $\mathrm{NaOCl}$ and SAF was used for 30 seconds under constant irrigation with $5 \mathrm{~mL}$ of $\mathrm{NaOCl}$ using the Vatea irrigation device, followed by irrigation with $3 \mathrm{~mL}$ of EDTA and $5 \mathrm{~mL}$ of NaOCl. Group II (ProTaper) was irrigated with $5 \mathrm{~mL}$ of $\mathrm{NaOCl}$, the F2 instrument was used for 30 seconds, followed by irrigation with $5 \mathrm{~mL}$ of $\mathrm{NaOCl}, 3 \mathrm{~mL}$ of EDTA, and $5 \mathrm{~mL}$ of $\mathrm{NaOCl}$. In 3 teeth $\mathrm{Ca}(\mathrm{OH})$, was not removed (positive control) and in 3 teeth canals were not filled with $\mathrm{Ca}(\mathrm{OH})_{2}$ (negative control). Teeth were sectioned and prepared for the scanning electron microscopy. The amounts of residual $\mathrm{Ca}(\mathrm{OH})_{2}$, were evaluated in the middle and apical thirds using a 5-score system. Results: None of the techniques completely removed the $\mathrm{Ca}(\mathrm{OH})_{2}$ dressing. No difference was observed between SAF and ProTaper in removing $\mathrm{Ca}(\mathrm{OH})_{2}$ in the middle $(\mathrm{P}=0.11)$ and the apical $(P=0.23)$ thirds. Conclusion: The SAF system showed similar efficacy to rotary instrument for removal of $\mathrm{Ca}(\mathrm{OH})_{2}$ from mandibular incisor root canals.
\end{abstract}

Key words: Calcium hydroxide. Endodontics. Root canal therapy. Irrigation.

\section{INTRODUCTION}

The use of calcium hydroxide $\left[\mathrm{Ca}(\mathrm{OH})_{2}\right]$ as intracanal dressing has been recommended to induce apexification, to control internal and external inflammatory root reabsorption and in the treatment of necrotic teeth with periapical lesions ${ }^{2,6,7,17}$. However, failing to completely remove the dressing may interfere with the seal, adhesion, and penetration of endodontic sealers ${ }^{4,5,14}$, adversely affecting the clinical performance of the sealer and possibly the long-term prognosis of root canal therapy ${ }^{14}$.

The most commonly described method for $\mathrm{Ca}(\mathrm{OH})_{2}$ removal is the use of a master apical file at working length combined with the use of sodium hypochlorite $(\mathrm{NaOCl})$ irrigation and EDTA $^{3,13,20,21,23}$. Rotary instruments ${ }^{11,12}$, sonically or ultrasonically-activated tips ${ }^{3,24}$, and devices such as the CanalBrush ${ }^{22}$ in conjunction with irrigation have also been recommended. None of these methods, however, have been able to completely remove $\mathrm{Ca}(\mathrm{OH})_{2}$ from the root canal, especially in the apical third ${ }^{3,11}$.

The Self-Adjusting File - SAF (ReDent-Nova, Ra'anana, Israel) is a hollow cylindrical file recently launched in the market. Its thin compressible walls are made of a nickel-titanium mesh, allowing its shape to adapt to root canal's along the crosssection, as well as longitudinally. Therefore, the SAF will three-dimensionally conform to canals with circular or oval cross-section, allowing maintenance of the original canal shape. Moreover, the design 
of SAF allows continuous flow of irrigant through its hollow file, while the solution is continuously activated by its vibrating motion ${ }^{15,16}$.

According to $\mathrm{Gu}$, et al. $^{8}$ (2009), the continuous flow of fresh irrigant in conjunction with the vibrating motion may have positive effects on the cleaning ability, especially on the apical third of the root canal system, generally the most difficult portion to clean. Previous works have shown that SAF is efficacious for removing smear layer and debris, especially in the apical third ${ }^{1,10,15}$.

Due to SAF's irrigation system and its ability to adapt to root canals with different shapes, this system may represent an efficient method for removal of $\mathrm{Ca}(\mathrm{OH})_{2}$ from root canals.

The goal of the present study was to evaluate, by scanning electron microscopy (SEM), the efficacy of SAF in comparison to ProTaper in the removal of $\mathrm{Ca}(\mathrm{OH})_{2}$ from root canals.

\section{MATERIAL AND METHODS}

The Ethics Committee of the Institution in which the study was carried out approved the project and the use of extracted teeth from its teeth bank for research purpose (Process number 58/11). Thirty-six freshly extracted permanent human mandibular incisors with lengths varying from 19 to $21 \mathrm{~mm}$ were selected after radiographs were taken in both buccolingual and mesiodistal directions. Exclusion criteria were: root canals allowing introduction of an instrument exceeding ISO size 10 to the apical foramen, teeth presenting apical curvature or two root canals, teeth with previous endodontic treatment and presence of external or internal root reabsorption.

A small amount of composite resin (Z-100, 3M/ ESPE, Salt Lake City, UT, USA) was placed on each root tip to prevent irrigant extrusion from the apical foramen during root canal preparation and $\mathrm{Ca}(\mathrm{OH})_{2}$ removal.

After coronal access, the cervical and middle thirds were prepared using S1 and SX instruments (ProTaper System - Dentsply Maillefer, Ballaigues, Switzerland). The working length was established as $1.0 \mathrm{~mm}$ shorter than the canal length. Biomechanical preparation of the root canals was performed using ProTaper Universal rotary system (Dentsply Maillefer) from S1 to F2 driven at $250 \mathrm{rpm}$ with 1.6 $\mathrm{N} / \mathrm{cm}$ of torque using an electric engine (X-Smart; Dentsply Maillefer) under irrigation with $2.5 \%$ $\mathrm{NaOCl}$. After biomechanical preparation, the root canals were irrigated with $5 \mathrm{~mL}$ of $17 \%$ EDTA (Biodinâmica, Ibiporã, PR, Brazil) followed by 5.0 $\mathrm{mL}$ of $2.5 \% \mathrm{NaOCl}$, dried with absorbent paper points, and filled with $\mathrm{Ca}(\mathrm{OH})_{2}$ paste (Calen; S.S.White Artigos Dentários Ltda., Rio de Janeiro, RJ, Brazil), employing a Lentulo spiral. Radiographs were taken from a mesiodistal orientation, in order to confirm complete filling of the root canals. The coronal access cavities were sealed with a cotton pellet and Coltosol (Coltène, WhaleDent, Switzerland). All specimens were kept in a closed box with $100 \%$ relative humidity at $37^{\circ} \mathrm{C}$ for 7 days. After this period, the temporary coronal seal was removed and specimens were randomly distributed into 2 groups ( $n=15)$, according to the method used for $\mathrm{Ca}(\mathrm{OH})_{2}$ removal. In 3 teeth, $\mathrm{Ca}(\mathrm{OH})_{2}$ was not removed (positive control) and another 3 teeth were not filled with $\mathrm{Ca}(\mathrm{OH})_{2}$ (negative control).

The $\mathrm{Ca}(\mathrm{OH})_{2}$ dressing was removed by a single operator in the following sequences:

Group I (SAF): After irrigating the root canal with $5 \mathrm{~mL}$ of $2.5 \% \mathrm{NaOCl}$, the SAF was operated in root canal for 30 seconds under constant irrigation with $5 \mathrm{~mL}$ of $2.5 \% \mathrm{NaOCl}$. The SAF was operated with a vibrating hand piece at an amplitude of 0.4 $\mathrm{mm}$ and 5,000 vibrations/min, attached to a special irrigation device (Vatea, ReDent-Nova) ${ }^{16,18}$ that provided continuous flow of the irrigation solution at a rate of $10 \mathrm{~mL} / \mathrm{min}$. An in-and-out manual motion was continuously performed by the operator. After that, canals were irrigated with $3 \mathrm{~mL}$ of $17 \%$ EDTA, followed by $5 \mathrm{~mL}$ of $2.5 \% \mathrm{NaOCl}$.

Group II (ProTaper): After root canal irrigation with $5 \mathrm{~mL}$ of $2.5 \% \mathrm{NaOCl}$, the ProTaper F2 instrument was used for 30 seconds, followed by irrigation with $5 \mathrm{~mL}$ of $2.5 \% \mathrm{NaOCl}, 3 \mathrm{~mL}$ of $17 \%$ EDTA and $5 \mathrm{~mL}$ of $2.5 \% \mathrm{NaOCl}$. The ProTaper instrument was driven at $250 \mathrm{rpm}$ with $1.6 \mathrm{~N} / \mathrm{cm}$ of torque using an electric engine (X-Smart; Dentsply Maillefer).

For both groups, the irrigating solutions were placed in $5 \mathrm{~mL}$ syringes attached to a 30-gauge needle (Ultradent, South Jordan, UT, USA), which was placed $2 \mathrm{~mm}$ short of the working length. Canals were irrigated in an up-and-down motion, except during the use of SAF. The solutions were suctioned with a NaviTip (Ultradent), and the root canals were dried with absorbent paper points. All specimens were prepared by a single operator.

\section{SEM evaluation}

Longitudinal grooves were cut on the mesial and distal root surfaces with a diamond disk, preserving the inner shelf of dentin surrounding the canal. Roots were then sectioned using a chisel and a hammer. For SEM analysis, the specimens were dehydrated, fixed on aluminum stubs, sputtercoated with gold, and examined under a scanning electron microscopy at $20 \mathrm{kV}$ (EVO 50, Carl Zeiss, Oberkochen, Germany). The residual $\mathrm{Ca}(\mathrm{OH})_{2}$ was visualized under 500x magnification at 4 different fields in the apical and middle thirds. After general evaluation of the canal wall, 2 representative SEM photomicrographs were taken under 500x 
magnification at the middle and apical thirds of each specimen. The amount of $\mathrm{Ca}(\mathrm{OH})_{2}$ debris was scored using the following system: 1 - clean root canal wall, with only a few small debris particles; 2 - few small agglomerations of debris; 3 - many agglomerations of debris covering less than $50 \%$ of the root canal wall; 4 - more than $50 \%$ of the root canal wall covered by debris; and 5 - root canal wall completely or almost completely covered by debris ${ }^{9}$. Four calibrated examiners analyzed, independently and in a blind manner, $\mathrm{Ca}(\mathrm{OH})_{2}$. Ten specimens

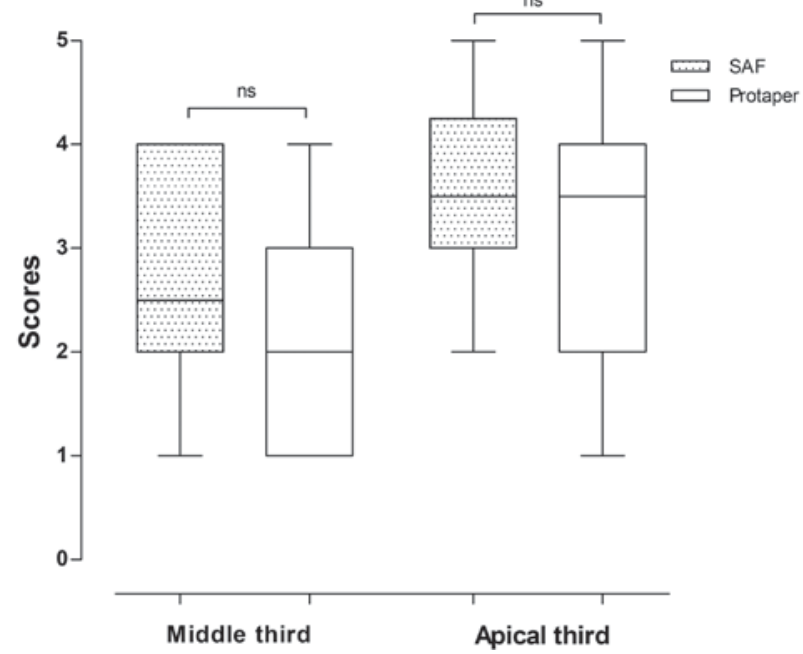

Figure 1- Comparison of the efficacy of Self-Adjusting File (SAF) and ProTaper for removal of $\mathrm{Ca}(\mathrm{OH})_{2}$ from the root canal. ns=non-significant were examined for calibration purpose. The scores were compared, and when a difference was found, the evaluators jointly examined the sample and its scoring, reaching an agreed score.

Data were analyzed by the Mann-Whitney nonparametric test at 5\% significance level, using the Graph Pad Prism 5 software (Graph Pad Software In., San Diego, California, USA).

\section{RESULTS}

None of the techniques was able to completely remove the $\mathrm{Ca}(\mathrm{OH})_{2}$ dressing. Figure 1 shows the comparison between groups. No difference was observed between SAF and ProTaper in removing $\mathrm{Ca}(\mathrm{OH})_{2}$ in the middle $(\mathrm{P}=0.11)$ and the apical $(P=0.23)$ thirds. The negative controls had no residues on the dentinal walls and the positive controls had the root canals completely filled with $\mathrm{Ca}(\mathrm{OH})_{2}$. SEM images representing the middle and apical thirds of each group are shown in Figure 2.

\section{DISCUSSION}

This study evaluated the efficacy of SAF compared with ProTaper rotary instrument for removal of a $\mathrm{Ca}(\mathrm{OH})_{2}$ dressing from root canals in mandibular incisors. SAF showed similar efficacy to ProTaper in removing $\mathrm{Ca}(\mathrm{OH})_{2}$.

Use of rotary instruments in conjunction with irrigation has been recommended for removal of $\mathrm{Ca}(\mathrm{OH})_{2}$ from root canals ${ }^{11,12}$. However, the authors
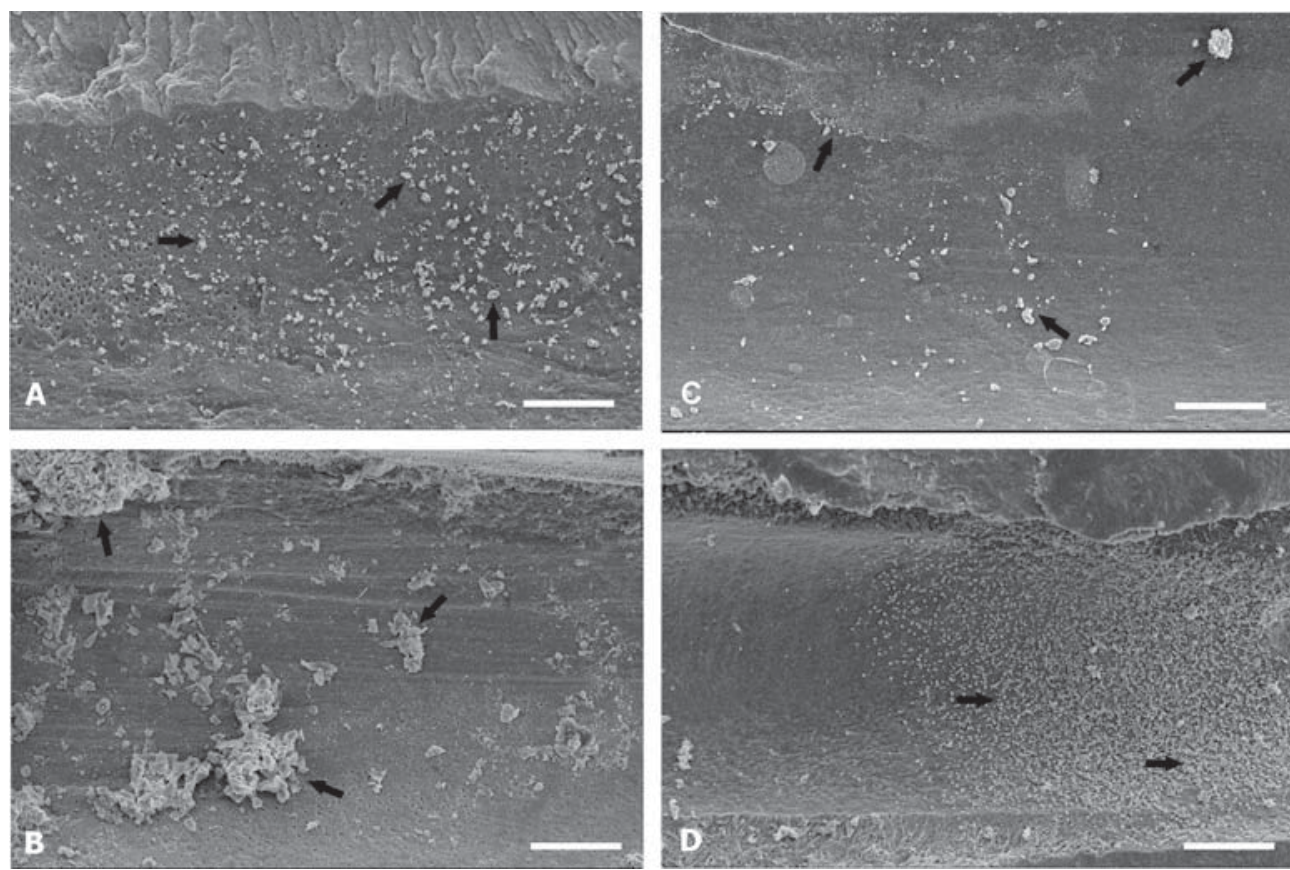

Figure 2- Scanning electron microscopy images representative of the Self-Adjusting File ( $A=$ middle third; $B=a p i c a l$ third) and ProTaper ( $C=$ middle third; $D=a p i c a l$ third) groups showing calcium hydroxide residues (arrows). $A$ and $C$ are representative of score 2: few small agglomerations of debris. B and D are representative of score 3: many agglomerations of debris covering less than $50 \%$ of the root canal wall. Scale bar=100 $\mu \mathrm{m}$ 
do not specify the length of time for which the instrument was used: these studies only mention the use of this type of instrument ${ }^{12}$ or their insertion to work length ${ }^{11}$ during the procedure. In the present study, after testing different lengths of time of SAF and ProTaper use for removal of $\mathrm{Ca}(\mathrm{OH})_{2}$ from root canals, the time selected was 30 seconds. This option was due to the fact that after 30 second, no $\mathrm{Ca}(\mathrm{OH})_{2}$ residues were observed in the solution suctioned from the root canal. Moreover, when compared with the usual time necessary for root canal instrumentation with SAF, 4 minutes $^{16}, 30$ seconds would have little or no impact on canal shape.

Achievement of thoroughly clean root canals depends on effective irrigant delivery, solution agitation $^{8}$, and its direct contact with the entire canal wall, particularly in the apical third8,25. SAF utilizes an irrigation device (Vatea; ReDent-Nova) which provides continuous flow of the irrigant during use. Since SAF is a hollow file, the irrigant enters the full length of the canal and is activated by the vibrating motion of the file's metal lattice, reportedly facilitating its cleaning and debridement effects $^{15}$. Moreover, SAF is able to adapt threedimensionally to the shape of the root canal ${ }^{16}$, and thus is expected to adapt to root canals prepared using any files, not necessarily SAF, during removal of $\mathrm{Ca}(\mathrm{OH})_{2}$.

According to the literature, the success of SAF for removal of debris and smear layer, especially in the apical third ${ }^{1,10,1}$, may be due to the vibrating motion of the file within the continuously replaced fluid, allied to the scrubbing effect of the file lattice against the root canal dentin ${ }^{10}$. Under the conditions of the present study, SAF used for 30 seconds showed similar efficacy to ProTaper in removing $\mathrm{Ca}(\mathrm{OH})_{2}$, regardless of the root third analyzed. It is possible that longer times of SAF use may remove more $\mathrm{Ca}(\mathrm{OH})_{2}$ by increasing the amount of time contact with the canal walls, as well as the amount of time of irrigant activation.

The rotary instrument shows efficacy similar to passive ultrasonic irrigation in removing $\mathrm{Ca}(\mathrm{OH})_{2}$ from root canals and removes significantly more $\mathrm{Ca}(\mathrm{OH})_{2}$ than only traditional needle irrigation. The explanation for this is that while the irrigants alone could not penetrate well into the apical third, the rotary instrument reaches the apical third of root canals favoring the $\mathrm{Ca}(\mathrm{OH})_{2}$ removal ${ }^{11}$.

A recent study used ProTaper or K3 Endo rotary instruments combined with $\mathrm{NaOCl}$ or EDTA to remove $\mathrm{Ca}(\mathrm{OH})_{2}$ from the root canals and showed that ProTaper was more effective than K3 Endo regardless of the irrigating solution used. The best results of ProTaper could be explained because the biomechanical preparation of root canals was performed with the ProTaper rotary system and consequently the ProTaper instrument had a better adaptation than $\mathrm{K} 3$ Endo instrument to the root canal walls ${ }^{12}$.

Various irrigants such as $\mathrm{NaOCl}$ and EDTA havs been investigated for removal of $\mathrm{Ca}(\mathrm{OH})_{2}$ from root canals $^{20,21}$. Rödig, et al. ${ }^{20}$ (2010) using the master apical file and irrigation with different solutions showed that $20 \%$ EDTA performed significantly better than $1 \% \mathrm{NaOCl}$. However, when rotary instruments are used for removal of $\mathrm{Ca}(\mathrm{OH})_{2}$ from root canal, there is no difference in the efficacy of $2.5 \% \mathrm{NaOCl}$ or $17 \%$ EDTA as a final rinse, showing that the rotary instrument has more influence than final irrigation solutions in the removal of $\mathrm{Ca}(\mathrm{OH})_{2}{ }_{2}^{12}$.

In the present study, neither SAF nor ProTaper were able to completely remove calcium hydroxide from the root canals. This is in agreement with results from previous studies, which showed the presence of $\mathrm{Ca}(\mathrm{OH})_{2}$ debris on the root canal walls regardless of the removal technique ${ }^{11,13,19,20,22}$. This highlights the need for further studies evaluating SAF use for increased times or other techniques for removal of $\mathrm{Ca}(\mathrm{OH})_{2}$ from root canal walls.

\section{CONCLUSION}

The SAF system showed similar efficacy to rotary instrument for removal of $\mathrm{Ca}(\mathrm{OH})_{2}$ from mandibular incisor root canals.

\section{ACKNOWLEDGEMENT}

This research was supported by the Fundação para o Desenvolvimento da UNESP (FUNDUNESP) by means of Research Grant to G. Faria (Process number: 00917/11-DFP).

\section{REFERENCES}

1- Adigüzel O, Yiğit-Özer S, Kaya S, Uysal I, Ganidağli-Ayaz S, Akkuş Z. Effectiveness of ethylenediaminetetraacetic acid (EDTA) and MTAD on debris and smear layer removal using a selfadjusting file. Oral Surg Oral Med Oral Pathol Oral Radiol Endod. 2011;112:803-8.

2- Ayna B, Ayna E, Celenk S. Endodontic and prosthetic treatment of teeth with periapical lesions in a 16-year-old-girl. J Appl Oral Sci. 2010;18:201-6.

3- Balvedi RP, Versiani MA, Manna FF, Biffi JC. A comparison of two techniques for the removal of calcium hydroxide from root canals. Int Endod J. 2010;43:763-8.

4- Barbizam JV, Trope M, Teixeira EC, Tanomaru-Filho M, Teixeira FB. Effect of calcium hydroxide intracanal dressing on the bond strength of a resin-based endodontic sealer. Braz Dent J. 2008;19:224-7.

5- Calt S, Serper A. Dentinal tubule penetration of root canal sealers after root canal dressing with calcium hydroxide. J Endod. 1999;25:431-3.

6- Faria G, Nelson-Filho P, Freitas AC, Assed S, Ito IY. Antibacterial effect of root canal preparation and calcium hydroxide paste (Calen) intracanal dressing in primary teeth with apical periodontitis. J Appl Oral Sci. 2005;13:351-5. 
7- Faria G, Silva RA, Fiori-Junior M, Nelson-Filho P. Re-eruption of traumatically intruded mature permanent incisor: case report. Dent Traumatol. 2004;20:229-32.

8- Gu LS, Kim JR, Ling J, Choi KK, Pashley DH, Tay FR. Review of contemporary irrigant agitation techniques and devices. J Endod. 2009;35:791-804.

9- Hülsmann M, Rümmelin C, Schäfers F. Root canal cleanliness after preparation with different endodontic handpieces and hand instruments: a comparative SEM investigation. J Endod. 1997;23:301-6.

10- Kaya S, Yiğit-Özer S, Adigüzel Ö. Evaluation of radicular dentin erosion and smear layer removal capacity of Self-Adjusting File using different concentrations of sodium hypochlorite as an initial irrigant. Oral Surg Oral Med Oral Pathol Oral Radiol Endod. 2011;112:524-30.

11- Kenee DM, Allemang JD, Johnson JD, Hellstein J, Nichol BK. A quantitative assessment of efficacy of various calcium hydroxide removal techniques. J Endod. 2006;32:563-5.

12- Kuga MC, Tanomaru-Filho M, Faria G, Só MV, Galletti T, Bavello JR. Calcium hydroxide intracanal dressing removal with different rotary instruments and irrigating solutions: a scanning electron microscopy study. Braz Dent J. 2010;21:310-4.

13- Lambrianidis T, Margelos J, Beltes P. Removal efficiency of calcium hydroxide dressing from the root canal. J Endod. 1999;25:85-8.

14- Margelos J, Eliades G, Verdelis C, Palaghias G. Interaction of calcium hydroxide with zinc oxide-eugenol type sealers: a potential clinical problem. J Endod. 1997;23:43-8.

15- Metzger Z, Teperovich E, Cohen R, Zary R, Paqué F, Hulsmann M. The self-adjusting file (SAF). Part 3: removal of debris and smear layer - a scanning electron microscope study. J Endod. 2010;36:697-702.

16- Metzger Z, Teperovich E, Zary R, Cohen R, Hof R. The selfadjusting file (SAF). Part 1: respecting the root canal anatomy - a new concept of endodontic files and its implementation. J Endod. 2010;36:679-90.
17- Mohammadi Z, Dummer PM. Properties and applications of calcium hydroxide in endodontics and dental traumatology. Int Endod J. 2011;44:697-730.

18- Peters OA, Boessler C, Paqué F. Root canal preparation with a novel nickel-titanium instrument evaluated with micro-computed tomography: canal surface preparation over time. J Endod. 2010;36:1068-72.

19- Rödig T, Hirschleb M, Zapf A, Hülsmann M. Comparison of ultrasonic irrigation and RinsEndo for the removal of calcium hydroxide and Ledermix paste from root canals. Int Endod J. 2011;44:1155-61.

20- Rödig T, Vogel S, Zapf A, Hülsmann M. Efficacy of different irrigants in the removal of calcium hydroxide from root canals. Int Endod J. 2010;43:519-27.

21- Salgado RJ, Moura-Netto C, Yamazaki AK, Cardoso LN, Moura AA, Prokopowitsch I. Comparison of different irrigants on calcium hydroxide medication removal: microscopic cleanliness evaluation. Oral Surg Oral Med Oral Pathol Oral Radiol Endod. 2009;107:580-4.

22- Taşdemir T, Celik D, Er K, Yildirim T, Ceyhanli KT, Yeşilyurt C. Efficacy of several techniques for the removal of calcium hydroxide medicament from root canals. Int Endod J. 2011;44:505-9.

23- Victorino FR, Bramante CM, Zapata RO, Casaroto AR, Garcia RB, Moraes IG, et al. Removal efficiency of propolis paste dressing from the root canal. J Appl Oral Sci. 2010;18:621-4.

24- Wiseman A, Cox TC, Paranjpe A, Flake NM, Cohenca N, Johnson JD. Efficacy of sonic and ultrasonic activation for removal of calcium hydroxide from mesial canals of mandibular molars: a microtomographic study. J Endod. 2011;37:235-8.

25- Zehnder M. Root canal irrigants. J Endod. 2006;32:389-98. 